\title{
Improving Ideal Performance of Hollow Fiber Carbon Membrane for $\mathrm{H}_{2} / \mathrm{N}_{2}$ Separation
}

Jaya, M. A. T., Tarmizi, M. H., Yusop, M. F. M., Ahmad, M. A., Gonawan, F. N., Nizam, M. K. and Ismail, A. F.

To Link this Article: http://dx.doi.org/10.6007/IJARBSS/v11-i1/9014

DOI:10.6007/IJARBSS/v11-i1/9014

Received: 09 December 2020, Revised: 10 January 2021, Accepted: 16 January 2021

Published Online: 29 January 2021

In-Text Citation: (Jaya et al., 2021)

To Cite this Article: Jaya, M. A. T., Tarmizi, M. H., Yusop, M. F. M., Ahmad, M. A., Gonawan, F. N., Nizam, M. K., \& Ismail, A. F. (2021). Improving Ideal Performance of Hollow Fiber Carbon Membrane for H2/N2 Separation. International Journal of Academic Research in Business and Social Sciences, 11(1), 903-920.

\section{Copyright: (c) 2021 The Author(s)}

Published by Human Resource Management Academic Research Society (www.hrmars.com)

This article is published under the Creative Commons Attribution (CC BY 4.0) license. Anyone may reproduce, distribute, translate and create derivative works of this article (for both commercial and non-commercial purposes), subject to full attribution to the original publication and authors. The full terms of this license may be seen at: http://creativecommons.org/licences/by/4.0/legalcode

Vol. 11, No. 1, 2021, Pg. 903 - 920

Full Terms \& Conditions of access and use can be found at http://hrmars.com/index.php/pages/detail/publication-ethics 


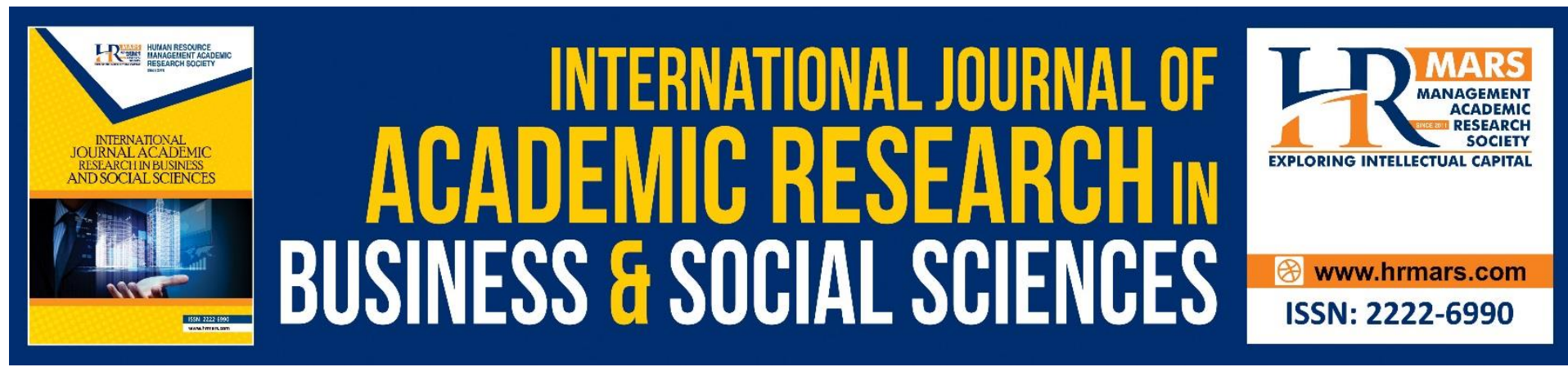

\title{
Improving Ideal Performance of Hollow Fiber Carbon Membrane for $\mathrm{H}_{2} / \mathrm{N}_{2}$ Separation
}

\author{
Jaya, M. A. T. ${ }^{1}$, Tarmizi, M. H. ${ }^{1}$, Yusop, M. F. M. ${ }^{2}$, Ahmad, M. \\ A. ${ }^{2}$, Gonawan, F. N. ${ }^{2}$, Nizam, M. K. ${ }^{3}$ and Ismail, A. F. ${ }^{4}$ \\ ${ }^{1}$ Kolej GENIUS Insan, Universiti Sains Islam Malaysia, Malaysia, ${ }^{2}$ School of Chemical \\ Engineering, Universiti Sains Malaysia, Malaysia, ${ }^{3}$ Bio-Aromatics Research Centre of \\ Excellence, Universiti Malaysia Pahang, Malaysia, ${ }^{4}$ Advanced Membrane Technology \\ Research Centre, Universiti Teknologi Malaysia, Malaysia
}

\begin{abstract}
Poly (2,6-dimethyl-1,4-phenylene oxide)(PPO) was successfully converted into hollow fiber carbon membrane for $\mathrm{H}_{2} / \mathrm{N}_{2}$ separation study. The ideal separation parameters were enhanced by tuning the pyrolysis temperature, heating rate, and thermal soak time utilizing the Robeson's 2008 upperbound and commercial boundary to obtain maximum balanced point between permeability and ideal selectivity. Using this approach, the optimum $\mathrm{H}_{2}$ permeability and $\mathrm{H}_{2} / \mathrm{N}_{2}$ ideal selectivity was 2868 Barrer and 586, respectively. SEM images depicted the surface of the PPO and carbon membranes were both dense, non-porous, symmetrical, and homogeneous. The estimated thickness of the carbon membranes was 14$15 \mu \mathrm{m}$. The permeability study indicated that the transport mechanism of the $\mathrm{H}_{2}$ across the membrane layer was dominated by molecular sieving. Excessively high or very low pyrolysis temperature reduced the $\mathrm{H}_{2}$ permeability and $\mathrm{H}_{2} / \mathrm{N}_{2}$ ideal selectivity. The $\mathrm{H}_{2} / \mathrm{N}_{2}$ ideal selectivity decreased against increasing heating rate as the $\mathrm{H}_{2}$ and $\mathrm{N}_{2}$ permeabilities increased significantly. Thermal soak time was highly effective in increasing the $\mathrm{H}_{2}$ permeability and $\mathrm{H}_{2} / \mathrm{N}_{2}$ ideal selectivity. Both $\mathrm{H}_{2}$ permeabilities and $\mathrm{H}_{2} / \mathrm{N}_{2}$ permselectivity from the binary test were considerably lower than the ideal separation values due to competitive gas transport through the membrane pore which was completely dominated by the larger $\mathrm{N}_{2}$.
\end{abstract}

Keywords: $\mathrm{H}_{2} / \mathrm{N}_{2}$ Separation, Poly(2,6-dimethyl-1,4-phenylene oxide), Poly( $p$-phenylene oxide), Optimization, Carbon Membrane.

\section{Introduction}

Owing to low capital costs and high efficiency in energy consumption, membrane technology in gas separation has been considered as a competitive alternative to replace or integrate with the existing conventional technology such as pressure swing adsorption, cryogenic distillation, and amine absorption (Ismail \& David, 2001). Inorganic membranes, such as carbon membranes, which have good thermal and chemical resistance compared to polymeric membranes, have attracted increasing interest for gas separation under extreme conditions. Such robust membranes are highly promising in natural gas processing, landfill gas recovery, hydrogen recovery, olefin/paraffin separation, and air separation (Bhide \& Stern, 
1993; Kim, Park, \& Lee, 2003; Koros \& Mahajan, 2000; White, Blinka, Kloczewski, \& Wang, 1995).

In early development, most of the carbon membranes showed attractive high selectivity but normally at the expense of very low permeability (Ismail \& David, 2001). After years of development, carbon membrane has demonstrated significant progress towards a more balanced performance, exhibiting both high selectivity and permeability. The capability for separation behavior, known as molecular sieving, is attributed to the pore size approaching the size of diffusing molecules and high porosity, thereby providing massive channels for the diffusion. This turbostratic structure of the carbon membrane can discriminate gases with similar kinetic diameters, such as $\mathrm{O}_{2}$ and $\mathrm{N}_{2}$.

The development of carbon membranes encompasses several critical variables, such as polymer precursor selection, pyrolysis temperature, heating rate, thermal soaking time, and heating atmosphere. Other variables include polymer structure modification, secondary materials, polymer solution concentration, and permeation conditions. In general, the common polymer precursors used for fabricating carbon membranes can be divided into polyimides and non-polyimides. Examples of polyimides are Kapton (Hatori, Yamada, \& Shiraishi, 1992; Suda \& Haraya, 1995), 6FDA-based polyimide (Geiszler \& Koros, 1996; Jones \& Koros, 1994; Ma, Lin, Wei, \& Kniep, 2016), polyimide BPDA-pp'ODA (Hayashi, Mizuta, Yamamoto, Kusakabe, \& Morooka, 1997), polyimide BPDA/pPDA (Fuertes \& Centeno, 1998), polyimide BPDA-DDBT/DABA (Okamoto et al., 1999), and Matrimid (Sazali et al., 2015). Considering the high cost of most of the polyimides, alternatives and non-polyimide polymers have been used, such as poly(vinylidene chloride) (Rao \& Sircar, 1993), poly(furfuryl alcohol) (Acharya at al., \& Lerou, 1997; Chen \& Yang, 1994), phenolic resin (Centeno \& Fuertes, 1999; Katsaros et al., 1997), poly ( $p$-phenylene oxide) (Yoshimune, Fujiwara, Suda, \& Haraya, 2005), and novolac resin (Tanco et al., 2015).

Recently, hydrogen recovery has received attention because of the increasing demand for hydrogen, which is widely utilized in the petroleum industry, particularly hydroalkylation, hydrodesulfurization, and hydrocracking. Hydrogen is also regarded as an environmentally friendly energy carrier (Yun \& Oyama, 2011). The hydrogen production requires separation and purification from other byproducts, such as $\mathrm{N}_{2}$ in ammonia production. The research progress on carbon membranes for $\mathrm{H}_{2} / \mathrm{N}_{2}$ separation is summarized in Figure 1 , which presents several excellent carbon membranes. The highest $\mathrm{H}_{2}$ permeabilities were 6080 Barrer (Wang, Zeng, \& Wang, 1996), 5387 Barrer (Zhang et al., 2014), and 5100 Barrer (Shusen, Meiyun, \& Zhizhong, 1996), which were produced using unsupported thin films of phenol-formaldehyde (PFR) and resorcinol-formaldehyde (RFR) resins as precursors. The highest $\mathrm{H}_{2} / \mathrm{N}_{2}$ permselectivities were 1086 (Campo, Magalhães, \& Mendes, 2010), 725 (Llosa Tanco, Pacheco Tanaka, \& Mendes, 2015), and 614.7 (Kita, Yoshino, Tanaka, \& Okamoto, 1997), which were produced using cellophane paper, tubular supported PFR/alumina, and thin-film polypyrrolone, respectively, as precursors. Llosa Tanco, Pacheco Tanaka, and Mendes (2015) fabricated an optimum carbon membrane that exhibited the best balance between permeability and permselectivity, which were 1731.3 Barrer and 725, respectively, with respect to the Robeson's 2008 upperbound (Robeson, 2008) and commercial boundary (Go, Lee, Shamsudin, Kim, \& Othman, 2016). The membrane was produced by vacuumassisted dip-coating of mixture of PFR and boehmite sol, and then pyrolyzed at $550{ }^{\circ} \mathrm{C}$ with 
heating rate and thermal soaking time of $1{ }^{\circ} \mathrm{C} / \mathrm{min}$ and $2 \mathrm{~h}$, respectively. The membrane was aged for $24 \mathrm{~h}$ and reactivated before testing. The deposited water reacted with the carbon active sites and formed oxygen functional groups, which caused a decrease in pore size that effectively hindered the $\mathrm{N}_{2}$ diffusion.

Improving the performance of the carbon membrane is to increase the membrane productivity and efficiency. The selectivity and permeability need to be balanced and it is unique for different gas separation. Too high selectivity but extremely low permeability or vice versa is undesirable. Previous works have suggested several ways to improve the performances by adding secondary materials (Li et al., 2015; Teixeira et al., 2014; Zhang et al., 2015), discovering new materials (Itta \& Tseng, 2011; Shusen et al., 1996; Zhang et al., 2009), altering the microstructure of the polymeric precursor (Li et al., 2014; Yoshimune et al., 2005). However, the values of the performance fall outside the desired region. Therefore, Robeson's upperbound (Robeson, 2008) and the suggested boundary of commercially attractive (Go et al., 2016) as shown in Figure 1 can be used to guide the researchers to make sure the improvement of the permeability and selectivity is oriented to fall within the boundary and obtain the desired optimum points. From this point, necessary improvements such as addition of secondary materials can be continued accordingly. It has been reported that the microstructure of carbon membrane, in which eventually determines the gas diffusion and selectivity, can be controlled and adjusted by controlling the pyrolysis parameters which are pyrolysis temperature, heating rate and soak time (Saufi \& Ismail, 2004). This work is to show that the carbon membrane pyrolysis and its corresponding performances can be directed into the optimum area of desirable permeability and selectivity. This is a simple and new approach to enhance the carbon membrane performance without integrating or introducing new secondary materials or creating new or micro-altering precursors. According to He and Hägg (2011), the pyrolysis temperature is the most dominant factor in affecting the permeability and ideal selectivity, followed by heating rate and thermal soak time which is used in this study. 


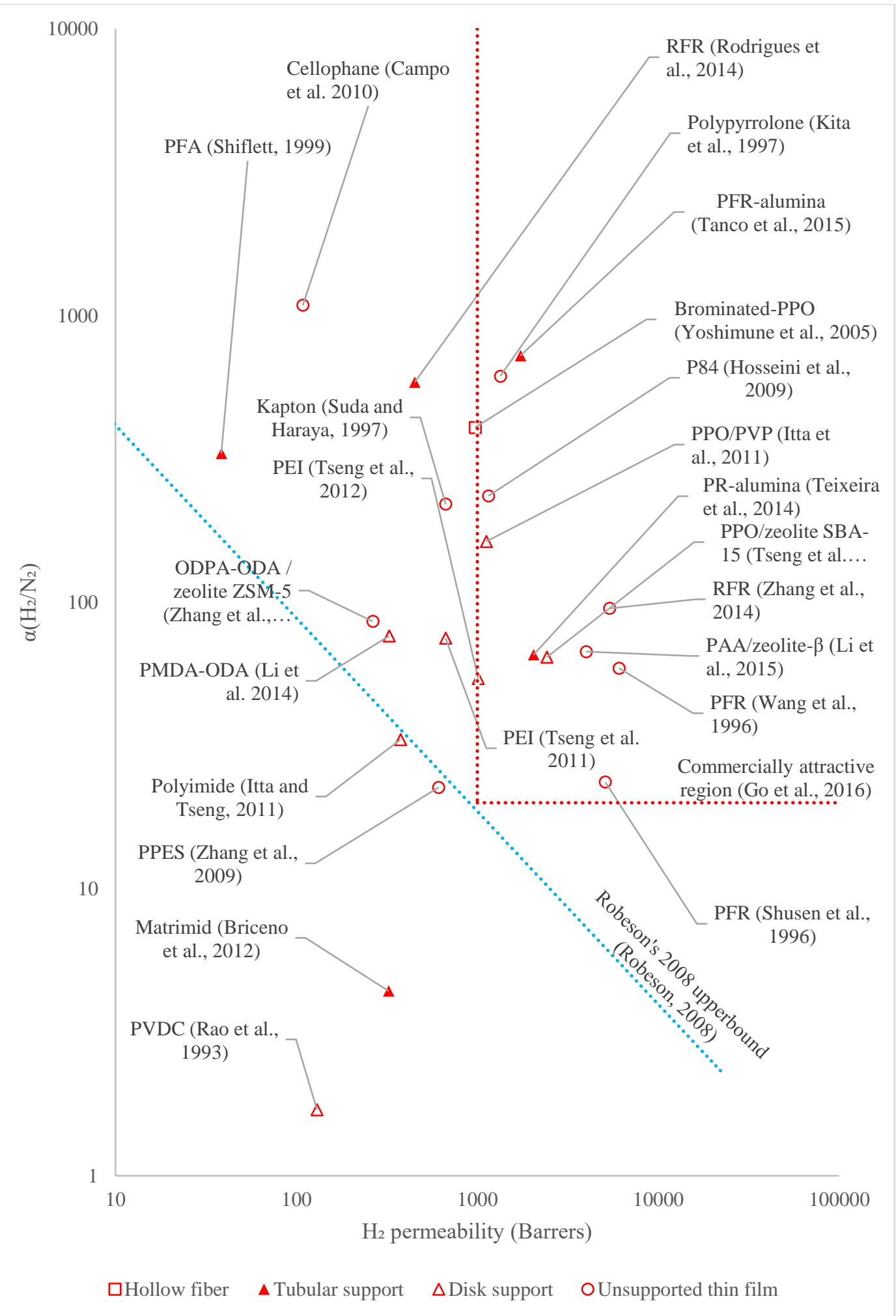

Figure 1. $\mathrm{H}_{2} / \mathrm{N}_{2}$ performance of carbon membranes compared with the Robeson's 2008 upperbound.

\section{Research Methodology - Materials and Method}

The PPO powder was purchased from Sigma-Aldrich (US). A 20 wt\% of PPO polymer solution was prepared using chloroform (purity 99.5\%) as the solvent with vigorous stirring (1000 rpm) for 30 mins. Before it was spun into a hollow fiber polymeric membrane, the 
polymer solution was left for 30 mins at room temperature. The polymer solution was spun into a hollow fiber with the following parameters: air gap: $25 \mathrm{~cm}$; polymer solution flowrate: $0.25 \mathrm{~g} / \mathrm{min}$; bore fluid: $125 \mathrm{ml} / \mathrm{hr}$ ethanol; receiving bath: ethanol.

The freshly spun hollow fiber was left inside the bath for a day, cut, and dried in the oven for 30 mins. The fiber was thermostabilized at $240{ }^{\circ} \mathrm{C}$ for 45 mins under a continuous supply of air ( $50 \mathrm{ml} / \mathrm{min}$ ) and followed by pyrolysis under continuous nitrogen supply (50 $\mathrm{ml} / \mathrm{min}$ ). The pyrolysis temperature, heating rate, and thermal soak time were varied. All samples were kept inside a tight-closed desiccator.

A scanning electron microscope (SEM, Model Quanta FEG 450, FEI, USA) was used to capture the images of the samples' cross-sections to analyze the morphology and estimate their thickness. Since the carbon membrane was brittle, epoxy was used to coat the samples before it was broken. The samples were crushed into powder for X-ray diffraction (XRD, Model PW 1820, Philips, USA) analysis to analyze the crystallinity of the samples. Small fragments of the samples were sent for thermogravimetric (TGA, Model STA6000, Perkin Elmer, USA) analysis.

A constant-pressure/variable-volume system was adopted to estimate the membrane flowrate in which a soap-bubble flow meter was used. For a single permeability test, the membrane fiber was bore-sided fed in which it was sealed at one end and opened at the other end to received pressurized gas. The test was beginning with $\mathrm{H}_{2}$, followed by $\mathrm{CH}_{4}$ and $\mathrm{CO}_{2}$. The $\mathrm{H}_{2}$ was also used to purge the membrane between the transitions from $\mathrm{CH}_{4}$ to $\mathrm{CO}_{2}$. The feed gauge pressure was 3.0 bar. The reading was taken after 18 hours of steady-state.

For the binary mixture experiment, the membrane was open-ended at both ends. The schematic diagram is shown in Figure 2 . The mixing tank was continuously purged to the atmosphere at $10 \mathrm{ml} / \mathrm{min}$ to preserve the feed concentration. The concentration of the feed gas was tuned using flow rate controllers and fine-tuned using pressure regulators placed before the controllers. The retentate was controlled with a flow controller.

\section{Results and Discussion}

\section{Morphology of the PPO and Carbon Membranes}

SEM images of the PPO and carbon membranes' cross-sectional views were depicted in Figures 2 which indicated the membrane structures were non-porous, dense, homogeneous and symmetrical. The estimated thickness of the carbon membrane was 14-15 $\mu \mathrm{m}$. The change of the morphology is due to thermal rearrangement during the pyrolysis ( $\mathrm{Xu}$, Rungta, \& Koros, 2011). It also involves partial decomposition of the polymer PPO in the thermostabilization stage and pyrolysis (Rivaton, 1995) as well as compaction (Sazali et al., 2015). 

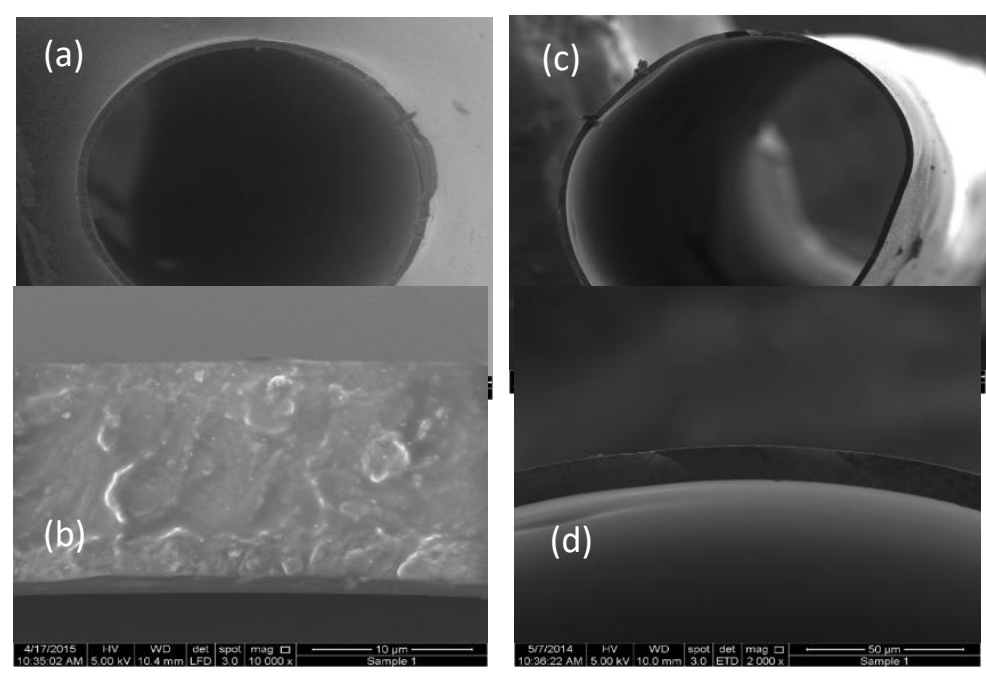

Figure 2. Physical and SEM images of cross-sectional views of PPO membrane $(a, b)$ and carbon membrane $(c, d)$

\section{Transport Mechanism of the Carbon Membranes}

In a carbon membrane, there are normally three possibilities of transport of gases molecules through its structure, which are Knudsen diffusion, selective surface diffusion, and molecular sieving, depending mostly on the nature of pore structure and pore size (Li, Wang, $\mathrm{Liu}, \mathrm{CaO}, \& \mathrm{Qiu}, 2012)$. Figure 3 shows the permeabilities of $\mathrm{H}_{2}, \mathrm{CO}_{2}, \mathrm{O}_{2}, \mathrm{CH}_{4}$, and $\mathrm{N}_{2}$ for the carbon membranes pyrolyzed at $500{ }^{\circ} \mathrm{C}(\mathrm{CM} 500), 600{ }^{\circ} \mathrm{C}(\mathrm{CM} 600)$, and $700{ }^{\circ} \mathrm{C}(\mathrm{CM} 700)$ with a heating rate and thermal soak time of $1{ }^{\circ} \mathrm{C} / \mathrm{min}$ and $0.25 \mathrm{hr}$, respectively. PPOM permeabilities were included for comparison purposes. The order of the gas on the $x$-axis was arranged according to the order of the gas kinetic diameters starting from the smallest $\left(\mathrm{H}_{2}\right)$ to the largest $\left(\mathrm{CH}_{4}\right)$. The decreasing trend of the permeabilities against the increasing kinetic diameter of the gases, as shown by the PPOM and CM600, suggested that the transport mechanism was governed by the molecular sieving effect (He \& Hägg, 2011; Itta, Tseng, \& Wey, 2011; Zhang, Wang, Zhang, Qiu, \& Jian, 2006).

The permeabilities of all gases except $\mathrm{CO}_{2}$ dropped significantly when the sample was pyrolyzed to $500^{\circ} \mathrm{C}$ due to the pre-mature development of the porous structure. As suggested by the TGA analysis in sub-chapter 4.3.3, at this pyrolysis stage, the decomposition of gases and structural rearrangement to create a highly porous structure was not sufficient for the diffusion of most non-adsorbable gases. These decomposed gases were responsible for creating the microporous channels on their way out (Norharyati \& Ismail, 2012; Wang et al., 1996; Wei, Qin, Hu, You, \& Chen, 2007). The amorphous structure originated from the thermostabilized PPOM gradually collapsed during the pyrolysis and chaotically rearranged as amorphous carbon (Lua \& Su, 2006). 


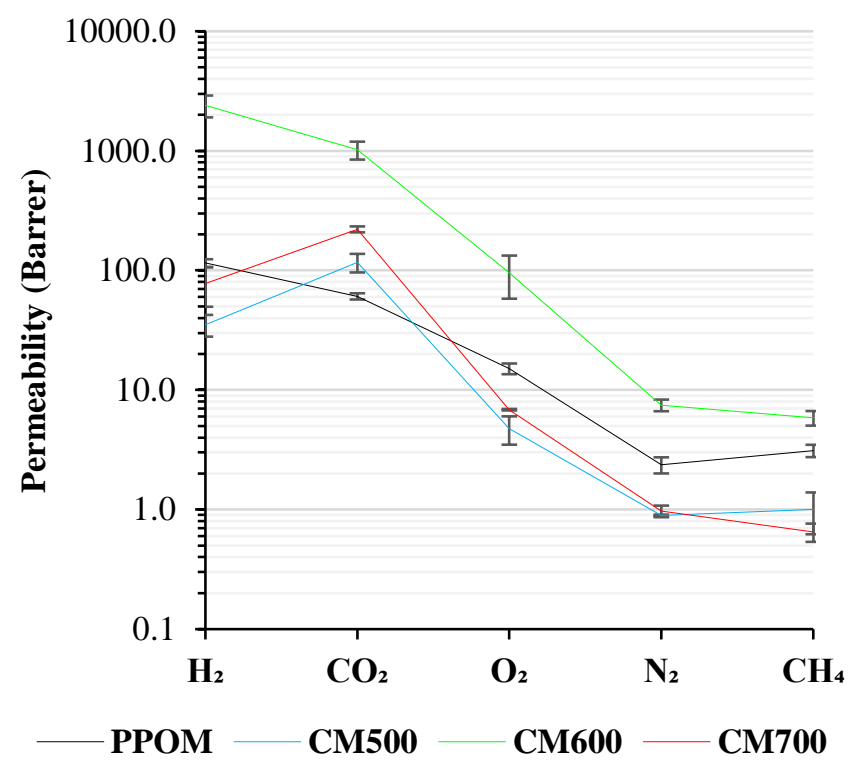

Figure 3. Permeabilities by carbon membrane prepared at different pyrolysis temperatures

\section{$\mathrm{H}_{2}$ Permeability and $\mathrm{H}_{2} / \mathrm{N}_{2}$ Ideal Selectivity of Carbon Membrane Against Pyrolysis Temperature}

The permeabilities of $\mathrm{H}_{2}$ and $\mathrm{N}_{2}$ and $\mathrm{H}_{2} / \mathrm{N}_{2}$ ideal selectivity against pyrolysis temperature are shown in Figure 4. After the PPO membrane was thermostabilized, and then pyrolyzed at $500{ }^{\circ} \mathrm{C}$, significant reductions of $\mathrm{H}_{2}$ and $\mathrm{N}_{2}$ permeabilities and $\mathrm{H}_{2} / \mathrm{N}_{2}$ ideal selectivity were observed because of the pre-mature development of the porous structure. During the thermostabilization, the PPOM underwent oxidative crosslinking, which caused the formation of highly-packed polymer chains in the membrane structure (Rivaton, 1995). The decomposition of gases started to occur during the pyrolysis, which created the microchannels when the decomposing gases were released (Fu, Sanders, Kulkarni, \& Koros, 2015). The decomposition coincided with thermal shrinkage, which was triggered by the increasing temperature on the membrane structure (Sazali et al., 2015).

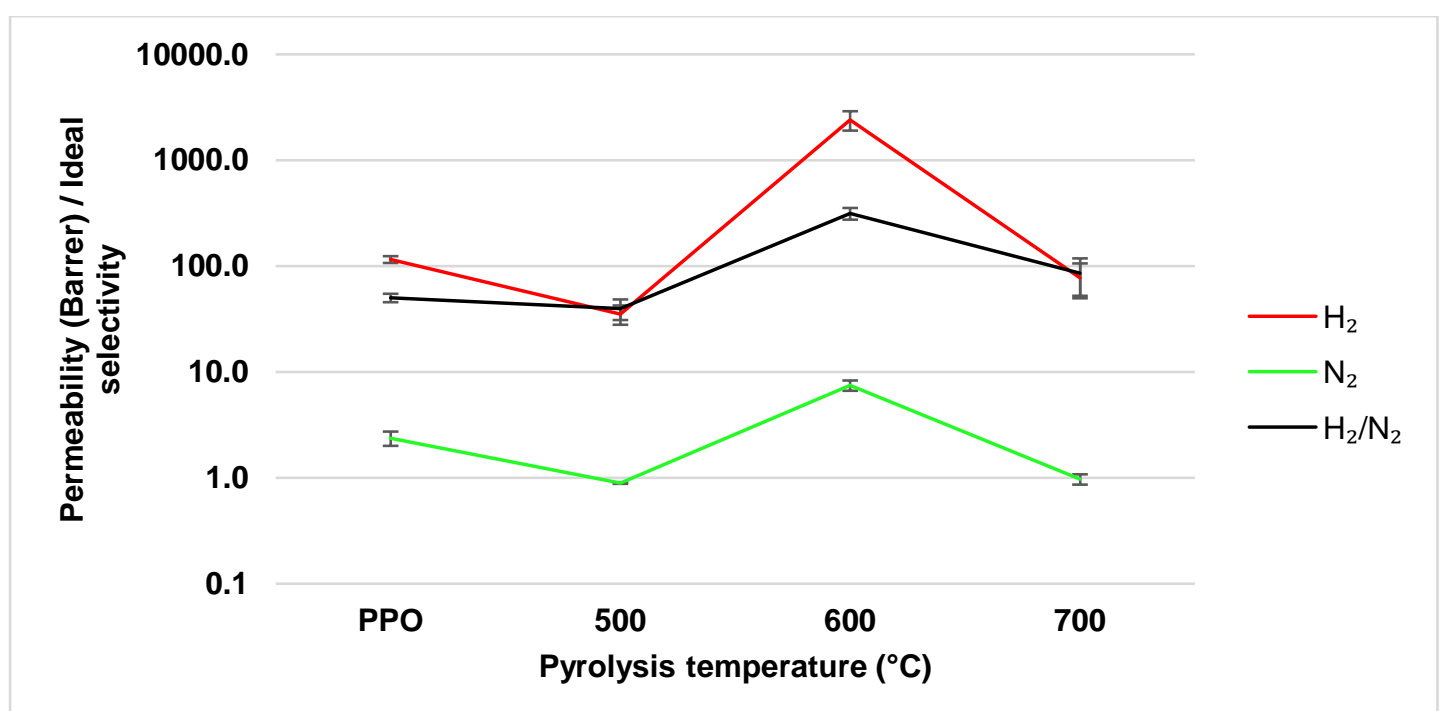

Figure 4. Permeabilities of $\mathrm{H}_{2}$ and $\mathrm{N}_{2}$ and $\mathrm{H}_{2} / \mathrm{N}_{2}$ ideal selectivity by PPO membrane and its carbon derivatives 
When the pyrolysis temperature was increased from 500 to $600{ }^{\circ} \mathrm{C}$, the $\mathrm{H}_{2}$ and $\mathrm{N}_{2}$ permeabilities increased significantly from 35.2 Barrer to 2401.9 Barrer and from 0.9 Barrer to 7.5 Barrer, respectively. The $\mathrm{H}_{2} / \mathrm{N}_{2}$ ideal selectivity was increased considerably as well given that the magnitude of increment of $\mathrm{H}_{2}$ permeability was relatively higher. This phenomenon was an indication of a well-developed pore structure with high porosity and ideal pore size for the separation. This phenomenon was believed to be due to dehydrogenation, in which a massive amount of hydrogen gas was released to establish a membrane structure with high porosity (Foley, 1995). The release also purged most of the entrapped and largely decomposed gases, such as carbon monoxide and carbon dioxide. The result also showed the absence of trade-off behavior between $\mathrm{H}_{2}$ permeability and $\mathrm{H}_{2} / \mathrm{N}_{2}$ ideal selectivity. A similar observation was shown by previous work (Campo et al., 2010). As the pyrolysis temperature was increased to $700{ }^{\circ} \mathrm{C}$, the $\mathrm{H}_{2}$ and $\mathrm{N}_{2}$ permeabilities and $\mathrm{H}_{2} / \mathrm{N}_{2}$ ideal selectivity decreased significantly because of thermal shrinkage, which led to decreased pore size and porosity (W. N. W. Salleh, Ismail, Matsuura, \& Abdullah, 2011). At this stage, the thermal shrinkage was more dominant than the gaseous decomposition factor. Based on Robeson's 2008 upper bound in Figure 5a, CM600 was the optimum carbon membrane for further enhancement.

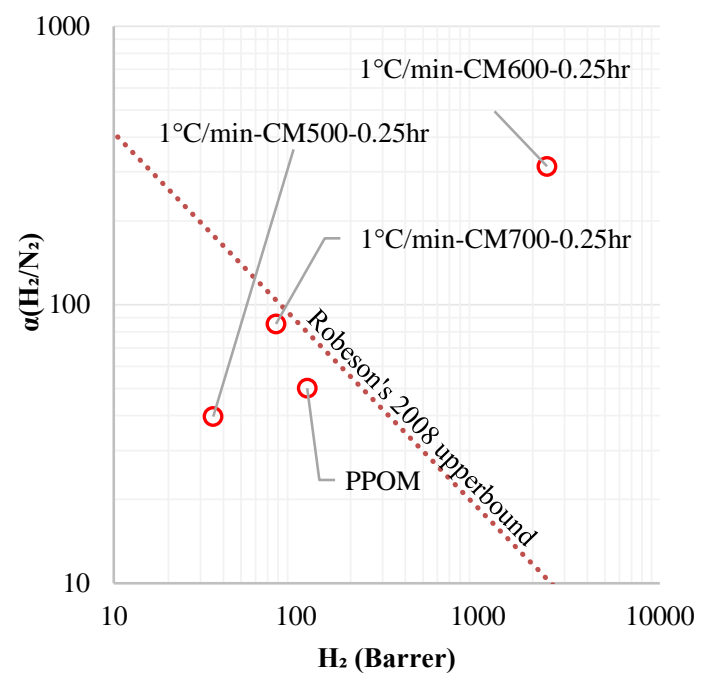

a) pyrolysis temperature

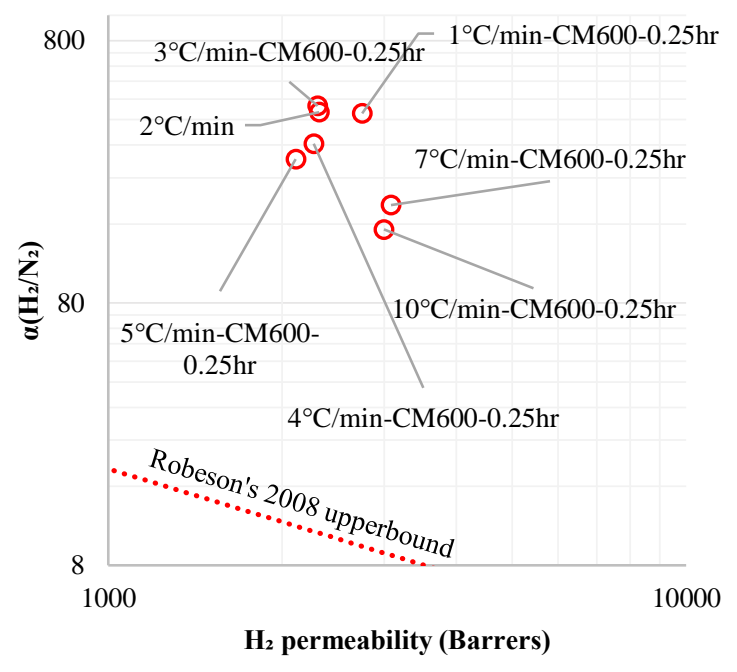

b) heating rate 


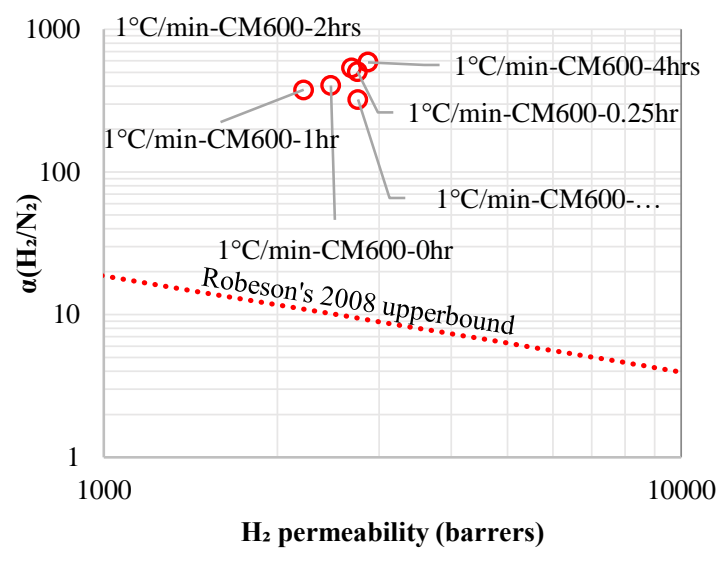

c) thermal soak time

Figure 5. Performances of the PPO and carbon membranes against Robeson's $2008 \mathrm{H}_{2} / \mathrm{N}_{2}$ upperbound at different pyrolysis conditions

\section{$\mathrm{H}_{2}$ Permeability and $\mathrm{H}_{2} / \mathrm{N}_{2}$ Ideal Selectivity of Carbon Membrane Against Heating Rate}

The heating rate was varied in the pyrolysis of CM600 with a thermal soaking time of $0.25 \mathrm{~h}$, as shown in Figure 6 . The $\mathrm{H}_{2}$ permeability indicated a slight increase after the heating rate at 7 and $10{ }^{\circ} \mathrm{C} / \mathrm{min}$. The increment of $\mathrm{N}_{2}$ permeability can be clearly seen from the decrease of $\mathrm{H}_{2} / \mathrm{N}_{2}$ ideal selectivity starting at $4{ }^{\circ} \mathrm{C} / \mathrm{min}$. The increase of permeabilities with increasing heating rate indicated that the $\mathrm{CM} 600$ received a minimum impact of thermal shrinkage because of a shorter period of thermal exposure. In addition, the endothermic decomposition would also cause a cooling effect that minimized the shrinkage effect on the pore structure. The lack of thermal shrinkage effect left the pore developed by the decomposing gases large in size, which has caused a significant reduction in the $\mathrm{H}_{2} / \mathrm{N}_{2}$ ideal selectivity. The thermal shrinkage during the pyrolysis was highly effective at a slower heating rate region (1-3 $\left.{ }^{\circ} \mathrm{C} / \mathrm{min}\right)$. The effect can be seen from the high $\mathrm{H}_{2} / \mathrm{N}_{2}$ ideal selectivity, with only a slight decrease of $\mathrm{H}_{2}$ permeability as compared with that at higher heating rates. According to Robeson's 2008 upper bound in Figure $5 \mathrm{~b}, 1^{\circ} \mathrm{C} / \mathrm{min}$ was the optimum heating rate to obtain $\mathrm{CM} 600$ with the best $\mathrm{H}_{2} / \mathrm{N}_{2}$ separation performance. 


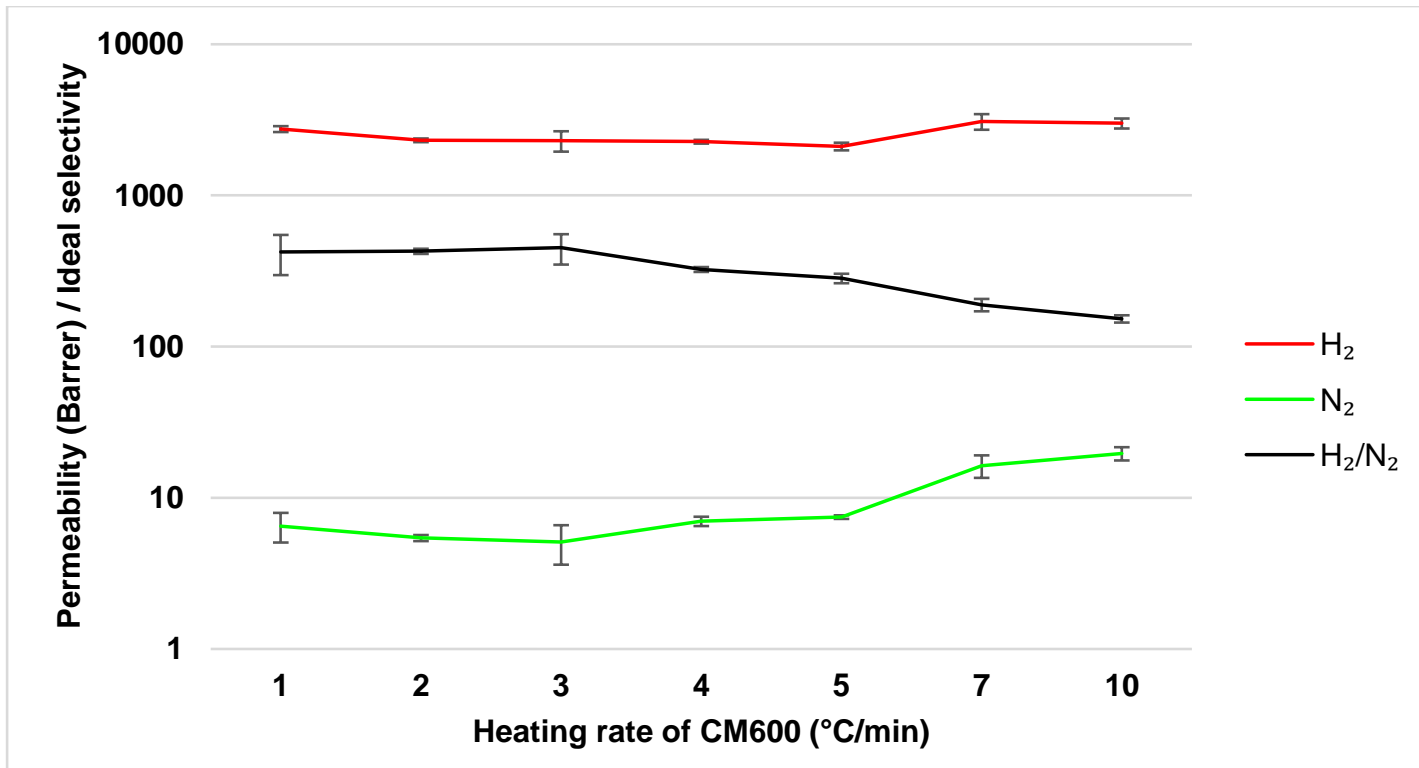

Figure 6. Permeabilities of $\mathrm{H}_{2}$ and $\mathrm{N}_{2}$, and $\mathrm{H}_{2} / \mathrm{N}_{2}$ ideal selectivity of $\mathrm{CM} 600$ against pyrolysis heating rate

$H_{2}$ permeability and $H_{2} / N_{2}$ ideal selectivity of carbon membrane against thermal soaking time

Figure 7 shows the $\mathrm{H}_{2} / \mathrm{N}_{2}$ permeability plot of sample $1{ }^{\circ} \mathrm{C} / \mathrm{min}-\mathrm{CM} 600$ against thermal soaking time. The $\mathrm{H}_{2}$ and $\mathrm{N}_{2}$ permeabilities indicated a consistent increase when thermal soak time was applied from 0 to $0.5 \mathrm{~h}$. The $\mathrm{H}_{2}$ and $\mathrm{N}_{2}$ permeabilities increased from 2474 and 6.2 to 2756 and 8.7 Barrer, respectively. The pore structure of the carbon membrane continued to develop as the decomposition continued. Besides that, some of the pores developed earlier were cleansed from entrapped decomposing gases.

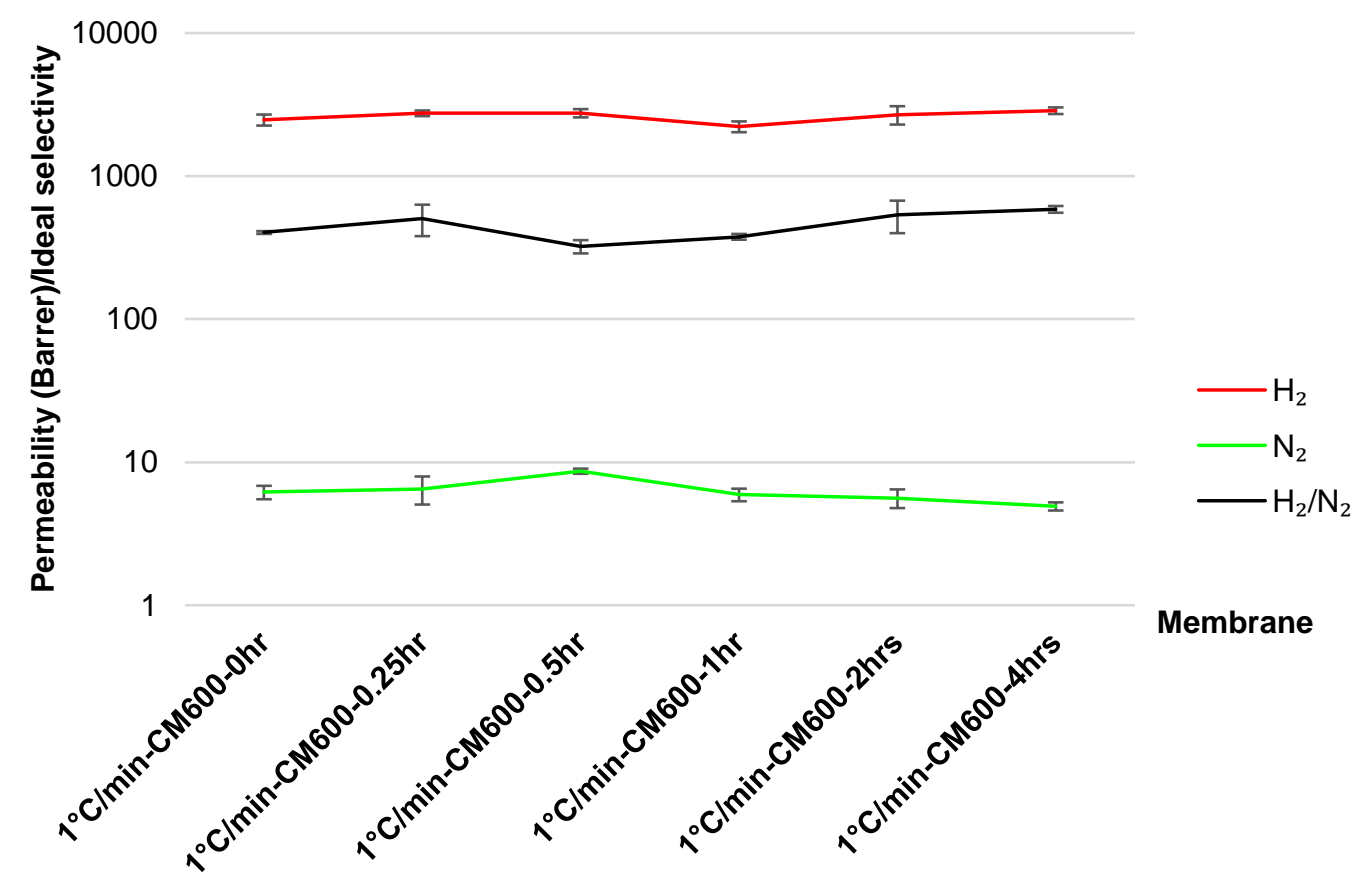

Figure 7. $\mathrm{H}_{2}$ and $\mathrm{N}_{2}$ permeabilities and $\mathrm{H}_{2} / \mathrm{N}_{2}$ ideal selectivities of $4{ }^{\circ} \mathrm{C} / \mathrm{min}-\mathrm{CM} 600$ against thermal soaking time 
However, a further increase of thermal soak time to $4 \mathrm{~h}$ caused the $\mathrm{N}_{2}$ permeability to decrease gradually, while the $\mathrm{H} 2$ permeability remained consistent gradually. This was a clear indication of the thermal sintering effect, which reduced the membrane pore size and densified the pore structure (Wan Norharyati Wan Salleh \& Ismail, 2012). The effect was more dominant against the larger $\mathrm{N}_{2}$ than the $\mathrm{H}_{2}$ indicating the porosity remained high since the decomposition replaced some of the pores collapsed due to the sintering effect (W. N.W. Salleh et al., 2011). The increase of $\mathrm{N}_{2}$ permeability against the thermal soaking time of 0 to $0.5 \mathrm{~h}$ decreased the $\mathrm{H}_{2} / \mathrm{N}_{2}$ ideal selectivity. On the other hand, the consistency of $\mathrm{H}_{2}$ permeability and gradual decrease of $\mathrm{N}_{2}$ permeability against the thermal soaking time between 1 to $4 \mathrm{~h}$ resulted in a significant increase of $\mathrm{H}_{2} / \mathrm{N}_{2}$ ideal selectivity from 322 to 586 . This result indicated that the membrane pores could be fine-tuned at a micro-scale by utilizing the thermal soak time to create a pore structure that obstructs large gases, with minimum impact on the smaller ones. As a result, the ideal selectivity of the $\mathrm{H}_{2} / \mathrm{N}_{2}$ was found to be at a maximum at the longer thermal soaking time. According to Robeson's 2008 upper bound in Figure $5 c$, the best thermal soaking time for optimum $\mathrm{H}_{2} / \mathrm{N}_{2}$ separation performance was four hours. The carbon membrane samples became highly fragile and brittle after eight hours of thermal soaking, which shattered after exposure to gas pressure higher than 1 bar. As shown in Figure 8, some samples were tearing open because of extreme densification; the tear was as wide as $0.25 \mathrm{~mm}$.

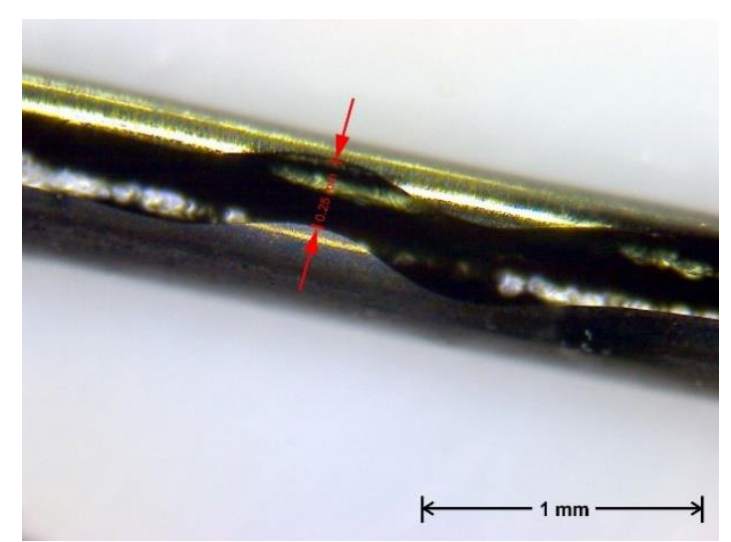

Figure 8 . Physical appearance of $1{ }^{\circ} \mathrm{C} / \mathrm{min}-\mathrm{CM} 600$ after $8 \mathrm{~h}$ of thermal soaking showing a tear stretching along the fiber

Figure 9 shows the CM600s after enhancement. The results are plotted together with that from previous works against Robeson's 2008 upper bound. The figures provide an overview of the current membranes in comparison with that in previous works for future improvement. Based on the single gas test, the performance of $1^{\circ} \mathrm{C} / \mathrm{min}-\mathrm{CM} 600-4 \mathrm{~h}$ hollow fiber carbon molecular sieve membrane was competitive. Besides, a balance between $\mathrm{H}_{2} / \mathrm{N}_{2}$ ideal selectivity and $\mathrm{H}_{2}$ permeability was observed compared with the PFR-based tubular supported carbon membrane by (Llosa Tanco, Pacheco Tanaka, \& Mendes, 2015). However, the $1{ }^{\circ} \mathrm{C} / \mathrm{min}-\mathrm{CM} 600-4 \mathrm{~h}$ was located under Robeson's 2008 upper bound for the mixture test because of extremely low $\mathrm{H}_{2} / \mathrm{N}_{2}$ permselectivity.

\section{Conclusion}

This paper presented the synthesis and enhancement of hollow fiber carbon membrane from PPO in terms of pyrolysis temperature, heating rate, and thermal soaking time based on the Robeson's upper bound and $\mathrm{H}_{2} / \mathrm{N}_{2}$ commercial boundary. The surface 
morphology of the 14-15- $\mu$ m-thick carbon membrane was dense, homogeneous, and symmetrical. The structure of the carbon membrane was amorphous, and the transport mechanism of $\mathrm{H}_{2}$ through the carbon membrane was dominated by molecular sieving. High pyrolysis temperature reduced the $\mathrm{H}_{2}$ permeability and $\mathrm{H}_{2} / \mathrm{N}_{2}$ ideal selectivity. Increasing the heating rate increased the $\mathrm{H}_{2}$ and $\mathrm{N}_{2}$ permeabilities but decreased the $\mathrm{H}_{2} / \mathrm{N}_{2}$ ideal selectivity. Increasing the thermal soaking time slightly increased the $\mathrm{H}_{2}$ permeability and decreased the $\mathrm{N}_{2}$ permeability, which resulted in increased $\mathrm{H}_{2} / \mathrm{N}_{2}$ ideal selectivity. The well-balanced $\mathrm{H}_{2}$ permeability and $\mathrm{H}_{2} / \mathrm{N}_{2}$ ideal selectivity from the single gas test was 2868.2 Barrer and 586, respectively. The study has shown that the carbon membrane performance enhancement through pyrolysis parameter adjustment, control, which can be well integrated to ensure the permeability and ideal selectivity obtained, is within the desired region. 
INTERNATIONAL JOURNAL OF ACADEMIC RESEARCH IN BUSINESS AND SOCIAL SCIENCES Vol. 11, No. 1, 2021, E-ISSN: $2222-6990$ @ 2021 HRMARS

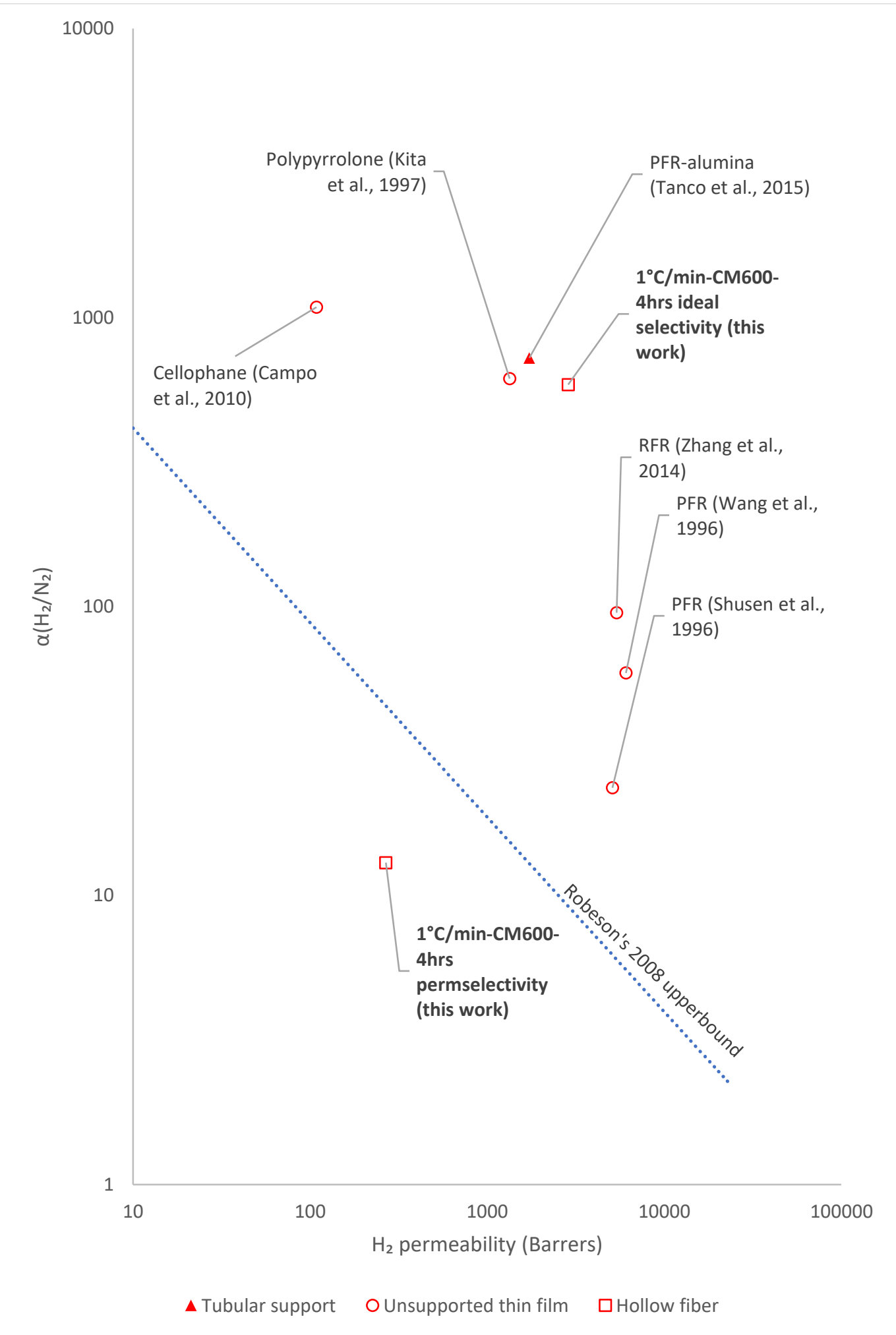

Figure 9. Performance of optimized CM600 in the current work and carbon membranes from previous works against Robeson's $2008 \mathrm{H}_{2} / \mathrm{N}_{2}$ upper bound

\section{Acknowledgment}

This research under project number 03-01-05-SF0418 was supported by Universiti Sains Malaysia (305/PJKIMIA/6013373). 


\section{Corresponding Author}

Professor Dr. Mohd Azmier Ahmad

Universiti Sains Malaysia, School of Chemical Engineering, Universiti Sains Malaysia, Engineering Campus, 14300 Nibong Tebal, Pulau Pinang, Malaysia

Email: chazmier@usm.my

\section{References}

Acharya, M., Raich, B. A., Foley, H. C., Harold, M. P., \& Lerou, J. J. (1997). Metal-Supported Carbogenic Molecular Sieve Membranes: Synthesis and Applications. Industrial \& Engineering Chemistry Research, 36(8), 2924-2930. doi:10.1021/ie960769d

Bhide, B. D., \& Stern, S. A. (1993). Membrane processes for the removal of acid gases from natural gas. I. Process configurations and optimization of operating conditions. Journal of Membrane Science, 81(3), 209-237. doi:https://doi.org/10.1016/03767388(93)85175-V

Campo, M., Magalhães, F., \& Mendes, A. (2010). Carbon molecular sieve membranes from cellophane paper. Journal of Membrane Science - J MEMBRANE SCI, 350, 180-188. doi:10.1016/j.memsci.2009.12.026

Centeno, T. A., \& Fuertes, A. B. (1999). Supported carbon molecular sieve membranes based on a phenolic resin. Journal of Membrane Science, 160(2), 201-211. doi:10.1016/S03767388(99)00083-6

Chen, Y. D., \& Yang, R. T. (1994). Preparation of Carbon Molecular Sieve Membrane and Diffusion of Binary Mixtures in the Membrane. Industrial \& Engineering Chemistry Research, 33(12), 3146-3153. doi:10.1021/ie00036a033

Foley, H. C. (1995). Carbogenic molecular sieves: synthesis, properties and applications. Microporous Materials, 4(6), 407-433. doi:https://doi.org/10.1016/09276513(95)00014-Z

Fu, S., Sanders, E. S., Kulkarni, S. S., \& Koros, W. J. (2015). Carbon molecular sieve membrane structure-property relationships for four novel 6FDA based polyimide precursors. Journal of Membrane Science, 487, 60-73.

doi:https://doi.org/10.1016/j.memsci.2015.03.079

Fuertes, A. B., \& Centeno, T. A. (1998). Preparation of supported asymmetric carbon molecular sieve membranes. Journal of Membrane Science, 144(1), 105-111. doi:https://doi.org/10.1016/S0376-7388(98)00037-4

Geiszler, V. C., \& Koros, W. J. (1996). Effects of Polyimide Pyrolysis Conditions on Carbon Molecular Sieve Membrane Properties. Industrial \& Engineering Chemistry Research, 35(9), 2999-3003. doi:10.1021/ie950746j

Go, Y., Lee, J. H., Shamsudin, I. K., Kim, J., \& Othman, M. R. (2016). Microporous ZIF-7 membranes prepared by in-situ growth method for hydrogen separation. International Journal of Hydrogen Energy, 41(24), 10366-10373.

doi:https://doi.org/10.1016/j.ijhydene.2015.09.060

Hatori, H., Yamada, Y., \& Shiraishi, M. (1992). Preparation of macroporous carbon films from polyimide by phase inversion method. Carbon, 30(2), 303-304.

oi:https://doi.org/10.1016/0008-6223(92)90094-D

Hayashi, J.-i., Mizuta, H., Yamamoto, M., Kusakabe, K., \& Morooka, S. (1997). Pore size control of carbonized BPDA-pp' ODA polyimide membrane by chemical vapor deposition of carbon. Journal of Membrane Science, 124(2), 243-251.

doi:https://doi.org/10.1016/S0376-7388(96)00250-5 
He, X., \& Hägg, M.-B. (2011). Optimization of Carbonization Process for Preparation of High Performance Hollow Fiber Carbon Membranes. Industrial \& Engineering Chemistry Research, 50, 8065-8072. doi:10.1021/ie2003279

Ismail, A. F., \& David, L. I. B. (2001). A review on the latest development of carbon membranes for gas separation. Journal of Membrane Science, 193(1), 1-18. doi:https://doi.org/10.1016/S0376-7388(01)00510-5

Itta, A. K., \& Tseng, H.-H. (2011). Hydrogen separation performance of CMS membranes derived from the imide-functional group of two similar types of precursors. International Journal of Hydrogen Energy, 36(14), 8645-8657. doi:https://doi.org/10.1016/j.ijhydene.2011.03.146

Itta, A. K., Tseng, H.-H., \& Wey, M.-Y. (2011). Fabrication and characterization of PPO/PVP blend carbon molecular sieve membranes for $\mathrm{H} 2 / \mathrm{N} 2$ and $\mathrm{H} 2 / \mathrm{CH} 4$ separation. Journal of Membrane Science, 372(1), 387-395.

doi:https://doi.org/10.1016/j.memsci.2011.02.027

Jones, C. W., \& Koros, W. J. (1994). Carbon molecular sieve gas separation membranes-I. Preparation and characterization based on polyimide precursors. Carbon, 32(8), 14191425. doi:https://doi.org/10.1016/0008-6223(94)90135-X

Katsaros, F. K., Steriotis, T. A., Stubos, A. K., Mitropoulos, A., Kanellopoulos, N. K., \& Tennison, S. (1997). High pressure gas permeability of microporous carbon membranes. Microporous Materials, 8(3), 171-176. doi:https://doi.org/10.1016/S09276513(96)00080-6

Kim, Y. K., Park, H. B., \& Lee, Y. M. (2003). Carbon molecular sieve membranes derived from metal-substituted sulfonated polyimide and their gas separation properties. Journal of Membrane Science, 226(1), 145-158. doi:https://doi.org/10.1016/j.memsci.2003.08.017

Kita, H., Yoshino, M., Tanaka, K., \& Okamoto, K.-i. (1997). Gas permselectivity of carbonized polypyrrolone membrane. Chemical Communication, 1051-1052. oi:https://doi.org/10.1039/A700048K

Koros, W. J., \& Mahajan, R. (2000). Pushing the limits on possibilities for large scale gas separation: which strategies? Journal of Membrane Science, 175(2), 181-196. doi:https://doi.org/10.1016/S0376-7388(00)00418-X

Li, L., Song, C., Jiang, H., Qiu, J., \& Wang, T. (2014). Preparation and gas separation performance of supported carbon membranes with ordered mesoporous carbon interlayer. Journal of Membrane Science, 450, 469-477. doi:https://doi.org/10.1016/j.memsci.2013.09.032

Li, L., Wang, C., Wang, N., Cao, Y., \& Wang, T. (2015). The preparation and gas separation properties of zeolite/carbon hybrid membranes. Journal of Materials Science, 50(6), 2561-2570. doi:10.1007/s10853-015-8819-1

Li, L., Wang, T., Liu, Q., Cao, Y., \& Qiu, J. (2012). A high CO2 permselective mesoporous silica/carbon composite membrane for CO2 separation. Carbon, 50(14), 5186-5195. doi:https://doi.org/10.1016/j.carbon.2012.06.060

Tanco, L. M. A., Tanaka, P. D. A., \& Mendes, A. (2015). Composite-alumina-carbon molecular sieve membranes prepared from novolac resin and boehmite. Part II: Effect of the carbonization temperature on the gas permeation properties. International Journal of Hydrogen Energy, 40(8), 3485-3496.

doi:https://doi.org/10.1016/j.ijhydene.2014.11.025 
Tanco, L. M. A., Tanaka, P. D. A., Rodrigues, S. C., Texeira, M., \& Mendes, A. (2015). Compositealumina-carbon molecular sieve membranes prepared from novolac resin and boehmite. Part I: Preparation, characterization and gas permeation studies. International Journal of Hydrogen Energy, 40(16), 5653-5663. doi:https://doi.org/10.1016/j.ijhydene.2015.02.112

Lua, A. C., \& Su, J. (2006). Effects of carbonisation on pore evolution and gas permeation properties of carbon membranes from Kapton ${ }^{\circledR}$ polyimide. Carbon, 44(14), 2964-2972. doi:https://doi.org/10.1016/j.carbon.2006.05.028

Ma, X., Lin, Y. S., Wei, X., \& Kniep, J. (2016). Ultrathin carbon molecular sieve membrane for propylene/propane separation. 62(2), 491-499. doi:10.1002/aic.15005

Norharyati, W., \& Ismail, A. (2012). Fabrication and characterization of PEI/PVP-based carbon hollow fiber membranes for $\mathrm{CO} 2 / \mathrm{CH} 4$ and $\mathrm{CO} 2 / \mathrm{N} 2$ separation. AlChE Journal, 58. doi:10.1002/aic.13711

Okamoto, K.-i., Kawamura, S., Yoshino, M., Kita, H., Hirayama, Y., Tanihara, N., \& Kusuki, Y. (1999). Olefin/Paraffin Separation through Carbonized Membranes Derived from an Asymmetric Polyimide Hollow Fiber Membrane. Industrial \& Engineering Chemistry Research, 38(11), 4424-4432. doi:10.1021/ie990209p

Rao, M. B., \& Sircar, S. (1993). Nanoporous carbon membranes for separation of gas mixtures by selective surface flow. Journal of Membrane Science, 85(3), 253-264. doi:https://doi.org/10.1016/0376-7388(93)85279-6

Rivaton, A. (1995). Photochemical and thermal oxidation of poly(2,6-dimethyl-1,4-phenylene oxide). Polymer Degradation and Stability, 49(1), 11-20. doi:https://doi.org/10.1016/0141-3910(95)00059-U

Robeson, L. M. (2008). The upper bound revisited. Journal of Membrane Science, 320(1), 390400. doi:https://doi.org/10.1016/j.memsci.2008.04.030

Salleh, W. N. W., \& Ismail, A. F. (2012). Fabrication and characterization of PEI/PVP-based carbon hollow fiber membranes for $\mathrm{CO} 2 / \mathrm{CH} 4$ and $\mathrm{CO} 2 / \mathrm{N} 2$ separation. 58(10), 31673175. doi:10.1002/aic.13711

Salleh, W. N. W., Ismail, A. F., Matsuura, T., \& Abdullah, M. S. (2011). Precursor Selection and Process Conditions in the Preparation of Carbon Membrane for Gas Separation: A Review. Separation \& Purification Reviews, 40(4), 261-311. doi:10.1080/15422119.2011.555648

Saufi, S. M., \& Ismail, A. F. (2004). Fabrication of carbon membranes for gas separation-a review. Carbon, 42(2), 241-259. doi:https://doi.org/10.1016/j.carbon.2003.10.022

Sazali, N., Salleh, W. N. W., Nordin, M. N. A. H., Harun, Z., \& Ismail, A. F. (2015). Matrimidbased carbon tubular membranes: The effect of the polymer composition. 132(33). doi:10.1002/app.42394

Shusen, W., Meiyun, Z., \& Zhizhong, W. (1996). Asymmetric molecular sieve carbon membranes. Journal of Membrane Science, 109(2), 267-270. doi:https://doi.org/10.1016/0376-7388(95)00205-7

Suda, H., \& Haraya, K. (1995). Molecular sieving effect of carbonized kapton polyimide membrane. Journal of the Chemical Society, Chemical Communications(11), 1179-1180. doi:10.1039/C39950001179

Teixeira, M., Rodrigues, S. C., Campo, M., Tanaka, P. D. A., Tanco, L. M. A., Madeira, L. M., Mendes, A. (2014). Boehmite-phenolic resin carbon molecular sieve membranesPermeation and adsorption studies. Chemical Engineering Research and Design, 92(11), 2668-2680. doi:https://doi.org/10.1016/j.cherd.2013.12.028 
Wang, S., Zeng, M., \& Wang, Z. (1996). Carbon Membranes for Gas Separation. Separation Science and Technology, 31(16), 2299-2306. doi:10.1080/01496399608001048

Wei, W., Qin, G., Hu, H., You, L., \& Chen, G. (2007). Preparation of supported carbon molecular sieve membrane from novolac phenol-formaldehyde resin. Journal of Membrane Science, 303(1), 80-85. doi:https://doi.org/10.1016/j.memsci.2007.06.055

White, L. S., Blinka, T. A., Kloczewski, H. A., \& Wang, I. f. (1995). Properties of a polyimide gas separation membrane in natural gas streams. Journal of Membrane Science, 103(1), 7382. doi:https://doi.org/10.1016/0376-7388(94)00313-N

Xu, L., Rungta, M., \& Koros, W. J. (2011). Matrimid ${ }^{\circledR}$ derived carbon molecular sieve hollow fiber membranes for ethylene/ethane separation. Journal of Membrane Science, 380(1), 138-147. doi:https://doi.org/10.1016/j.memsci.2011.06.037

Yoshimune, M., Fujiwara, I., Suda, H., \& Haraya, K. (2005). Novel Carbon Molecular Sieve Membranes Derived from Poly(phenylene oxide) and Its Derivatives for Gas Separation. Chemistry Letters - CHEM LETT, 34, 958-959. doi:10.1246/cl.2005.958

Yun, S., \& Ted Oyama, S. (2011). Correlations in palladium membranes for hydrogen separation: A review. Journal of Membrane Science, 375(1), 28-45. doi:https://doi.org/10.1016/j.memsci.2011.03.057

Zhang, B., Dang, X., Wu, Y., Liu, H., Wang, T., \& Qiu, J. (2014). Structure and gas permeation of nanoporous carbon membranes based on RF resin/F-127 with variable catalysts. Journal of Materials Research, 29(23), 2881-2890. doi:10.1557/jmr.2014.327

Zhang, B., Shen, G., Wu, Y., Wang, T., Qiu, J., Xu, T., \& Fu, C. (2009). Preparation and Characterization of Carbon Membranes Derived from Poly(phthalazinone ether sulfone) for Gas Separation. Industrial \& Engineering Chemistry Research, 48(6), 2886-2890. doi:10.1021/ie8013583

Zhang, B., Wang, T., Zhang, S., Qiu, J., \& Jian, X. (2006). Preparation and characterization of carbon membranes made from poly(phthalazinone ether sulfone ketone). Carbon, 44(13), 2764-2769. doi:https://doi.org/10.1016/j.carbon.2006.03.039

Zhang, B., Wu, Y., Lu, Y., Wang, T., Jian, X., \& Qiu, J. (2015). Preparation and characterization of carbon and carbon/zeolite membranes from ODPA-ODA type polyetherimide. Journal of Membrane Science, 474, 114-121.

doi:https://doi.org/10.1016/j.memsci.2014.09.054 